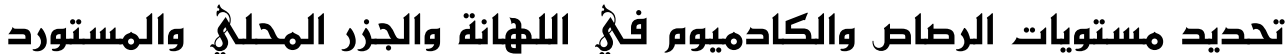

\author{
زينب علي طالب تويج \\ جامعة النرات الأوسط التثنية -معرد تقني كوفة-قسم الصيدلة \\ Zainbtweij1098@gmail.com
}

الخلاصة

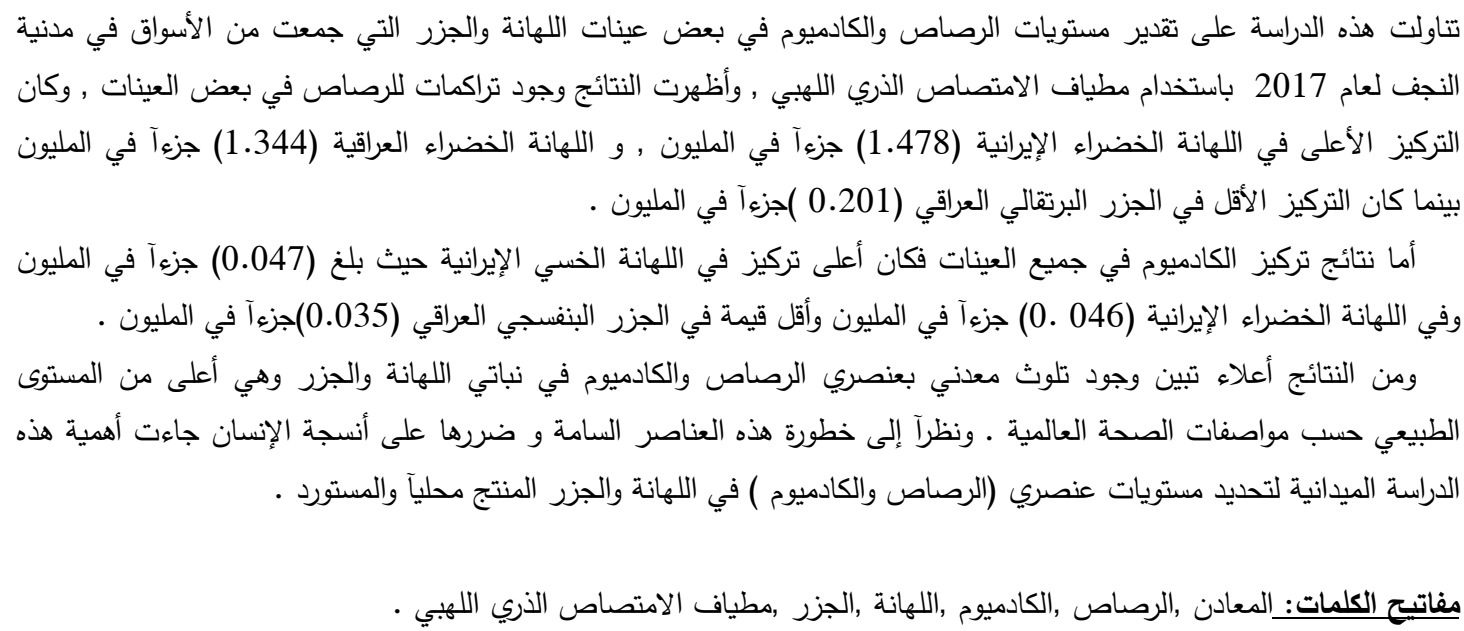

\section{Determination of Lead and Cadmium Levels in Local and Imported Carrots and Cabbage}

\author{
Zainab Ali Talib Tweij
}

\begin{abstract}
This study was conducted on the determination of levels of lead and cadmium in some samples of cabbage and carrots .which was collected from the markets and the most crowded people in the Najaf city of 2017, using an atomic absorption spectrometer .

Results showed lead accumulation in some samples the highest concentration was in the Iranian green cabbage (1.478)part per million and the green cabbage of Iraqi (1.344) part per million , while the lowest concentration was in the Iraqi orange carrots (0.201) part per million .

Results of cadmium concentration in all samples, the highest concentration was in Iranian cabbage (0.047) part per million and Iranian green cabbage (0.046) part per million, the lowest value in the Iraqi violet carrots $(0.035)$ part per million and the Iraqi yellow carrots $(0.040)$ part per million .

A higher result indicates that there are metal accumulations of lead and cadmium in cabbage and carrot compared with permitted levels according to the World Health Standards because of the seriousness of these elements and harmful to human tissue for all these reasons ,this field study is important to determine the levels of elemental (lead and cadmium) in the cabbage and carrots produced locally and imported.
\end{abstract}

Keywords: metal ,lead ,cadmium ,cabbage ,carrot, atomic absorption spectrometer the flame. 
يعزى التلوث المعدني للتربة والنباتات إلى نشاطات الإنسان الصناعية المتعددة من صهر للمعادن وطلائها وسائر الأعمال المعدنية الأخرى بالإضافة إلى صناعة الجلود ودباغتها وذلك لما تنفثه هذه المواد من غازات ودخان وما تسربه من كيمياويات إلى الماء وما تخلفه من نفايات صلبة ـ تساهم النشاطات الناتجة من اتساع المدن وتطورها وما يرافقها من مخلفات متعددة في تلوث البيئة تعرف إجمالآ باسم مخلفات الددن , بالإضافة إلى بقايا الأسمدة والمبيدات [1].وتؤثر المعادن والعناصر الكيميائية الأخرى الموجودة في الغذاء في صحة الإنسان فبعضها له وظيفة بيولوجية مفيدة ومعروفة وبعضها الأخر ليس له وظيفة بيولوجية معروفة وقد يكون ضارا بصحة الإنسان , ومنها مركبات الرصاص المؤذية للجهاز العصبي الحركي • والكادميوم له تأثير على الوظيفة الكلوية [2] .ويعد الرصاص والكادميوم من العناصر الثقيلة وهي من أكبر الملوثات البيئة وأكثرها انتشارا حيث يوجد الرصاص في قشرة الأرض بكميات قليلة إلا أنه موجود في الغلاف الجوي بشكل أساسي نتيجة مصادره الصناعية [3] حيث يستخدم في صناعة السبائك وأنابيب شبكات مياه الثرب والخزف والذخائر الحربية والبطاريات ويدخل كمكون في صناعة الأصبغة والدهانات [4] ولكن تعد إضافة الرصاص للبنزين أحد المصادر الرئيسية التي يتعرض من خلالها الإنسان [7-5] وينعكس تلوث البيئة بالرصاص في تلوث الغذاء سوى كان في الخضر والحبوب والفاكهة , مما يؤثر على صحة وسلامة المستهلك ولا سيما الأطفال اذ يمتاز الرصاص بقدرته على عبور المشيمة مسببا بذلك انخفاض وزن الطفل بعد الولادة وضرر دماغ الجنين بصورة غير قابلة للعلاج [8].كما يسبب الرصاص أمراض القلب الوعائية نتيجة ارتفاع ضغط الدم واختلال وظيفة الكلية , ومسامية العظام وابيضاض الدم [9].أما عنصر الكادميوم فيوجد في الترب العادية بتركيز ضئيل (0.5)جزءآ في المليون أو أقل , لكن في التربة الرسوبية قد يصل تركيزه إلى (25) جزءآ في المليون ومن مصادر التلوث بالكادميوم بعض خامات الفوسفور واستخدام المخصبات التجارية ومرتبط مع تعدين الزنك ونتيجة لاستعماله الواسع في الصناعات منها صناعة الألواح الكهربائية والبطاريات وصناعة الاصباغ والانابيب البلاستيكية والمطاطية [10].وتعد الأسمدة من أهم مصادره اذ تؤدي الى تلوث التربة والمياه ويتميز بأنه يبقى في البيئة التي استقر بها لمدة طويلة بسبب انتقاله في التربة والماء ومن ثم الى النبات والأسماك والحيوانات [11] ويصبح له تأثير سمي عندما يتواجد بتراكيز عالية في التربة [4].ويعد الغذاء المصدر الأساسي لتعرض الإنسان للكادميوم بالإضافة إلى الهواء والماء ويمتص الجسم نصف الكمية الموجودة في الغذاء التي تتراوح بين (2-40) جزءا في المليون وأما الباقية فأن الجسم يتخلص منها عن طريق الإخراج في حالة الغذاء ويتم تخزين هذا العنصر في الكبد والكلية حيث يتم التخلص منه ببطء وفي حالة زيادة تركيزه في الجسم يسبب ضرراً للكلية وفي حالة التتفس بهواء عالي التركيز من الكادميوم يسبب ضررا جسيما للرئة , وكذلك تلف وأمراض الكبد و يسبب هشاشة في العظام وسرطان الرئة وقد يؤدي الى الوفاة [12].لذا يعد التلوث بالمعادن الثقيلة إحدى أشكال التلوث البيئي الناتج من نشاط الإنسان الصناعي أو الزراعي وفي السنوات الأخيرة اهتم العلماء بدراسة العناصر الثثيلة من ناحية تواجدها في البيئة وتأثيراتها البيولوجية وعلاقة ذلك بصحة الإنسان ويعد الغذاء أحد المصادر الأساسية لتعرض الإنسان لهذه العناصر لذا اهتمت دراسات عديدة باستحداث الطرق الملائمة لتحدد مدى تلوث الغذاء 
بهذه العناصر ومدى ملاءمته للاستخدام الآدمي [13]تحديد الحد الأدنى أو التركيز الحرج المسموح به من هذه الملوثات في الغذاء من دون أن يحدث أضرارا [14].وبسبب تأثير هذه العناصر السامة و مضرها على صحة الإنسان جاءت أهمية هذه الدراسة لتقدير تراكيز عنصري (الرصاص والكادميوم ) في اللهانة والجزر ـ وذكر في الدراسات السابقة لبعض الدول العربية مثل ليبيا [ 15 ] نبين ان مستوى الرصاص و الكادميوم في بعض لرض لرصن الخضراوات كانت ما بين (0.4-16.5 ) جزءآ في المليون و (0.17-0.75) جزءآ في المليون وعلى التوالي , وفي دراسة اخرى [16] كان مستوى الرصاص ما بين (0.001-1.66) جزءآ في المليون ومستوى الكادميوم ما جا جرئ بين (0.001-0.04) جزءآ في المليون في الخضراوات .

اما الدراسات العالمية فهي كثيرة و متعدد منها [17] حيث توضح مستوى الرصاص والكادميوم في الخضراوات كان (0.01-16.5) جزءآ في المليون و (0.008-0.11) جزءآ في المليون وعلى التوالي .كما أوضح [18] هناك اختلاف في تحديد الحدود المسموح بها من الرصاص في الأغذية ما بين بعض بلدان العالم كما هو

موضح في الجدول رقم (1)

جدول (1) الحدود المسموح بها من الرصاص جزآ في المليون في الأغذية بعض بلدان العالم .

\begin{tabular}{|c|c|c|}
\hline الأغذية & بلدان العالم & ت \\
\hline 1.5 & كندا & 1 \\
\hline 0.5 & السويد & 2 \\
\hline 1.0 & بريطانيا & 3 \\
\hline 1.0 & نيوزيلاندا & 4 \\
\hline 0.36 & المكسيك & 5 \\
\hline 2.0 & المانيا & 6 \\
\hline 2.5 & استراليا & 7 \\
\hline
\end{tabular}

\section{طرائق العمل}

جمعت العينات من اللهانة والجزر من أسواق مدينة النجف خلال شهر كانون الثاني لعام 2017.

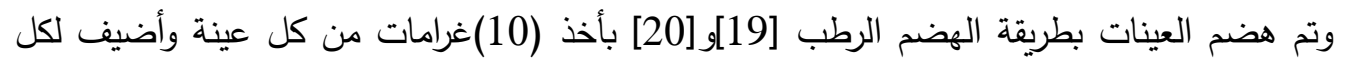
عينة مزيج (1:3) حجما من الحوامض المركزة(حامض البيروكلوريك وحامض النتريك ) ثم وضعها في لئ دورق زجاجي مغطى بزجاجة ساعة في حمام مائي لمدة ساعة واحدة تحت درجة حرارة (80)خ ,ثم تبرد 
وترشح العينات باستخدام اوراق ترشيح وينقل المحلول إلى قنينة حجمية سعة (25) مل ويكمل الحجم إلى حد العلامة بماء منزوع الأيونات وتحفظ إلى إن تجرئ على عليه عملية الفحص بواسطة جهاز الامتصاص الذري اللهبي.

\section{النتائج والمناقثة}

يوضح الجدول (2)مستويات الرصاص في عينات اللهانة والجزر ويتضح ان أعلى قيمة وجدت في

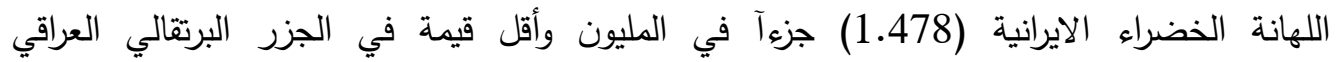
(0.201)جزءآ في المليون • ويعود السبب في هذا إلى أن الخضار الدرنية هي بتماس مباشر مع الديه

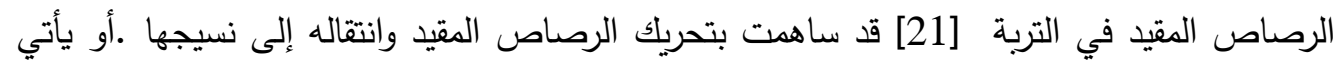
الرصاص إلى الخضار الورقية نظرآ لسعة سطح أوراقها , نتيجة الترسب المباشر على هذه الأجزاء

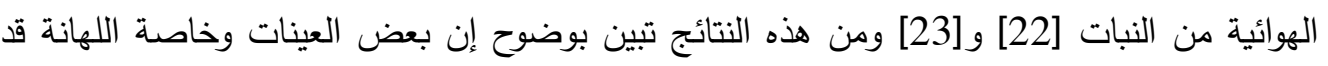
احتوى على مستويات من الرصاص أعلى من المستوى الطبيعي حيث ان الحد الأقصى لتركيز الرصاص في المواد الغذائية هو (1)جزءآ في المليون [24] وفي منظمة الصحة العالمية بتركيز (0.05)جزءا في المليون للرصاص كحد اقصى في مياه الشرب [25]. جدول رقم (2) تراكيز الرصاص في العينات قيد الدراسة

\begin{tabular}{|c|c|c|}
\hline تركيز جزء في المليون &  & ت \\
\hline 1.277 & اللهانة بنفسجية ايرانية & 1 \\
\hline 1.478 & اللهانة خضراء ايرانية & 2 \\
\hline 1.277 & اللهانة خضراء خسيه ايرانية & 3 \\
\hline 1.344 & اللهانة خضراء عراقية & 4 \\
\hline 1.075 & الجزر البرتقالي الايراني & 5 \\
\hline 0.941 & الجزر البنفجي العراقي & 6 \\
\hline 0.201 & الجزر البرتقالي العراقي & 7 \\
\hline 0.941 & الجزر الاصفر العراقي & 8 \\
\hline 1 & الطبيعية & \\
\hline
\end{tabular}

كما يوضح الجدول (3) التفاوت بين الحد الأعلى (0.047)جزءآ في المليون والحد الأدنى (0.035)جزءآ في المليون للكادميوم في أنواع اللهانة والجزر ويعكس اختلاف تركيز الكادميوم الى مواقع زراعة العينات ,ويدل على مدى مساهمة مواقع زراعة العينات في ارتفاع تركيز الكادميوم باللهانة والجزر المزروعة فمن المعروف أن الكادميوم من العناصر الثقيلة التي تتصف باحتمال امتصاصه من جذور النبات وإمكانية تجمعه في الأجزاء الخضراء ونقله أيضا إلى الأجزاء الثرة [23] وهي أعلى من الحد الأقصى في مياه الثرب بتركيز (0.005) جزءآ في المليون وحسب منظمة الصحة العالمية 
[25] وكما ذكرت توصيات كلا من [14] بأن الدد المسموح به من الكادميوم في الخضروات والفواكه

$$
\text { الطازجة هو (30) ميكروجرام /كيلوغرام - المام }
$$

جدول (3) تراكيز الكادميوم في عينات قيد الدراسة

\begin{tabular}{|c|c|c|}
\hline تركيز جزء في المليون & 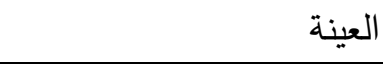 & $ت$ \\
\hline 0.0416 & اللهانة البنفسجية ايرانية & 1 \\
\hline 0.0468 & اللهانة الخضراء ايرانية & 2 \\
\hline 0.0474 & اللهانة الخضراء خسيه ايرانية & 3 \\
\hline 0.0433 & اللهانة الخضراء العراقية & 4 \\
\hline 0.0439 & الجزر البرتقالي الايراني & 5 \\
\hline 0.0352 & الجزر البنفسجي العراقي & 6 \\
\hline 0.0456 & الجزر البرتقالي العراقي & 7 \\
\hline 0.0404 & الجزر الاصفر العراقي & 8 \\
\hline 0.03 & الطبيعية & \\
\hline
\end{tabular}

يتبين من هذه الدراسة وجود تراكمات من الرصاص والكادميوم في عينات قيد الدراسة وخاصة اللهانة التي

تفوق الحدود المسموح بها عالمياً .وهنا يرجح فرضية إن تكون العناصر الضارة التي تطلق للغلاف الجوي أو تتتشر فوق سطح الأرض هي التي تحدث خلاً في النظام البيئي , وهي إما إن تكون غازية ممثلة في الغازات الضارة التي تطلقها عوادم السيارات بالإضافة إلى القمامة التي تتزايد بشكل مطرد من خلال تزايد السكان من ناحية وزيادة معدلات استهلاك الفرد من ناحية أخرى .وأيضا زيادة النشاطات الصناعية والسكانية .

1- Soylak, M.H. Cloak , and Turkoglu , O., Heavy metal , 2007 .

2- Murray , R.K. , Garner , D.K. , Mayes , P.A. , Rod well , V.W., Harper's Biochemistry, 25 ${ }^{\text {th }}$, ad , Appleton and Lange , P.660 , 2000.

3-Susainah , Ch.M. and Haj Ali, A., Honey as Bio indicator of Environmental contamination . $3^{\text {rd }}$. Alex .Conf. Fad. Sic-Tech, P(1-15), 1997.

4-Peralta ,J.R., Gardena - Torresdey , J.L., Thiemann ,K.J., Gomez,E., Artigas ,S., Rescan ,E. and parsons ,J.G., study of the effects of heavy metals on seed germination and plant growth on alfalfa plant (Medic ago Sativa) growth in solid media .,conference on hazardous , Waste Research .,P: 135-140, 2000 .

5-FAO /WHO ., Joint FAO/ WHO food standers program, codes Alimentations Commission contamination . CAC / Vol. VXII. FAO, Roma, 1984 .

6- U.S EPA, (United States Environment Protection Agency ) . Air rends report : Lead- 2007.

7 - لجنة التفاوض الحكومية الدولية . UNEP/FAO/PIC/INC الدورة الحادية عشر , جنيف , 8 ايلول/ سبتمبر 2004 البندة من جدول الاعمال المؤقت , صفحة 2004.68 . 
8- U.S. ATSDR., (United States Agency For Toxic Substances and Disease Registry) . Toxicological profile for lead . U.S. department of Health and Human services . 1-582, 2007.

9-EMEP/ CCC , European Monitoring and Evaluation Programmer chemical Coordination Center) Heavy metals and POP measurement, Available from : 2006 .http://torantula.nilalno/progects/ccc/repors/cccr 2006

10-Rahimi ,E.,Hashemi ,M. and Torki ,Z. ,Baghbadoran, Determination of cadmium and lead in human milk .Int. J. Environ. Sci. Tech. 6(4):671-676,2009.

11- Levy, A.S , Stevens , L.A, Schmidt, C.H. , Zhang, Y.P. , Castro , A.F. , Feldman , H.I. teal ., A new equation to estimate glomerular filtration rate . Annals of Internal Med , 150:604-607, 2009.

12-Wu ,F.B., Chen , F. ,Wei, K. and Zhang , G.P., Effect of Cadmium on free amino acid, glutathione and ascorbic acid concentration in two barley genotypes (Hoodlum Vulgarly) differing in cadmium tolerance. Chemosphere ,578:P.447454,2004.

13-U.S. Department of health and human Services ,public health service Agency for Toxic Substances and Disease Registry (ATSDR), Toxicological profile for cadmium, 2012.

14- Dahliya , A.S , Karper , R. , Hedge , A.G. and Shsrma , R.M. , Lead , cadmium and nickel in chocolate and candies from suburban areas Mumbai, India . Food compos. Anal. 18:517-522, 2005 .

15- مروان ,احمد نجاح , الأمن الغذائي و سلامة الغذاء ـ ندوة الأمن الغذائي الثانية , كلية الزراعة رجامعة

$$
\text { طرابلس , } 1996 .
$$

16-عمر ,علي سعيد و جمال ,حسن غيث و فاطمة سعيد و عادل سعد ,التلوث بالمعادن الثقيلة : تقدير

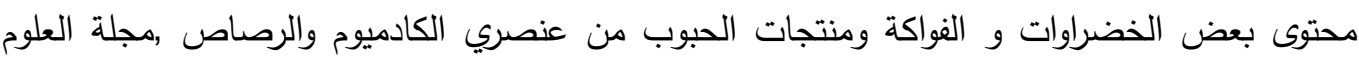

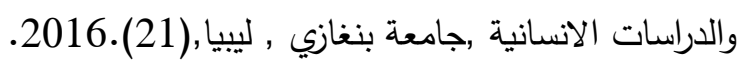

17-Ybanez,N. and Montero ,R. ,Trace Element Food Toxicology ;A-Growing Discipline Cri.Rev.Fd.Sci.Nut.36(4):299-320.1996.

18-Stelz,A.Georgii,S.Brunn,H. and Musket ,E. ,Contaminants in Food : Estimation of Daily Intake via Food .Deutsche Lebensmittel Rundschan 86 (1):10-12.1990.

19-Douglas , A.S. , Donald , M. , west fundamentals of analysis chemistry $.3^{\text {rd }}$ Es.1975.

20-Saracoglu , S., Saggy , K. ,Osgood , O. , Uluozlu , D., Tauzin, M. and soak , M., Determination of Trace element content of body foods from Turkey . food chem. 105:280-285,2007

21-Thornton,I., Chemical aspect of the distribution and from of heavy metals in soil .In: Pollution effect of heavy metals on plants ,Vol2 .(Leap ,N.Y. end).Applied Science Publisher .London .P. 1:35,1981.

22-Monuicon ,S.J., Szpunar, D., Andre ,D., Blake ,B. and Lipinski R., Concentration and Bio availabity of cadmium and lead in cocoa powder and related products .Food Addit Contam. 20:343-352,2003.

23-Mench ,M., Baize ,D., and Misquote, B., Cadmium availability to wheat in five soil series from the young district ,Burgundy, France .Environmental Pollution ,95,P.93-103, 1997.

24-FAO. Codex ,Aliment Arius ,Food and Agriculture organization ,NO,9239 W/M ,August ,United Nations ,1985.

25-السروي ,أحمد. الملوثات المائية (المصدر ,التأثير, التحكم و العلاج ), دار الكتب العلمية للنشر والتوزيع

,القاهرة ,جمهورية مصر العربية. 2008 , 
Journal of University of Babylon, Pure and Applied Sciences, Vol.(26), No.(6): 2018 